\title{
Resistive Switching Tuning Ferromagnetism and Near Band Edge Emission
} in Metal/ZnO:Cu/n $\boldsymbol{n}^{+}-\mathrm{ZnO}: \mathrm{Ga} / \mathrm{c}-$ Sapphire Structure*

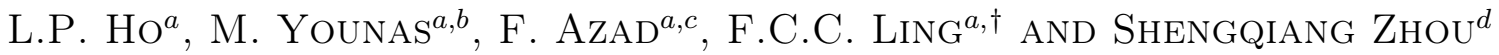 \\ ${ }^{a}$ Department of Physics, The University of Hong Kong, Pokfulam, Hong Kong, P.R. China \\ ${ }^{b}$ PCG, Physics Division, PINSTECH, Nilore, Islamabad 45650, Pakistan \\ ${ }^{c}$ School of Natural Sciences (SNS), National University of Sciences and Technology (NUST), \\ H-12 Islamabad, Pakistan \\ ${ }^{d}$ Helmholtz-Zentrum Dresden-Rossendorf, Institute of Ion Beam Physics and Materials Research, \\ Bautzner Landstr. 400, 01328, Dresden, Germany
}

(Received November 14, 2018; revised version January 29, 2019; in final form March 6, 2019)

\begin{abstract}
A metal/ZnO:Cu/ $n^{+}-\mathrm{ZnO}: \mathrm{Ga} / \mathrm{c}$-sapphire structure was fabricated using the pulsed laser deposition. With biased applied across the metal and the $n^{+}$-Ga-doped $\mathrm{ZnO}$ whereas the Ga-doped $\mathrm{ZnO}$ was grounded and $I-V$ measurement conducted with the voltage sequence of $0 \mathrm{~V} \rightarrow+$ ve bias $\rightarrow 0 \mathrm{~V} \rightarrow$-ve bias $\rightarrow 0 \mathrm{~V}$, resistive switching was observed while the resistance transited from high state to low state at $\approx+1.5 \mathrm{~V}$ and reset to high state while the sample was reversely biased. SQUID measurement shows that the sample is ferromagnetic at room temperature, and the magnetic moment is tunable, having a reduction of $\approx 30 \%$ during the high state to low state switching. X-ray photoelectron spectroscopy study shows an increase in $\mathrm{Cu}^{+}: \mathrm{Cu}^{2+}$ oxidation state ratio during the high state to low state transition. Similar resonance state tunable on near band edge emission intensity is observed, with the intensity reduced by $\approx 30 \%$ during the high state to low state transition but the defect emission intensity does not change. The physics leading to the resonance state tuning of magnetic moment and near band edge emission intensity is discussed.
\end{abstract}

DOI: 10.12693/APhysPolA.136.122

PACS/topics: ferromagnetism, near band edge emission, Cu-doped $\mathrm{ZnO}$

\section{Introduction}

Defect mediated room temperature ferromagnetism (RTFM) and materials with magnetization tunable by external electric bias are attractive and interesting physical phenomena not only in the fundamental aspect but also in terms of having impact in applications. In the aspect of UV emitting devices, electric bias tuning near band edge (NBE) emission is also an attractive phenomenon for applications. $\mathrm{ZnO}$ is a wide band gap semiconductor having potential applications in optoelectronic, transparent conductive electrode, transparent electronic, and spintronics, etc. [1].

$\mathrm{Cu}$-doped $\mathrm{ZnO}$ is particularly interesting because neither its, nor its oxide are FM at RT. Herng et al. [2] proposed a microscopic indirect double exchange model for explaining the FM in $\mathrm{Cu}$-doped $\mathrm{ZnO}$, in which the FM is aligned by the electron hopping between the $\mathrm{Cu}$ having +1 and +2 oxidation states $\left(\mathrm{Cu}^{+}\right.$and $\left.\mathrm{Cu}^{2+}\right)$ in the vicinity of the overlapping $\mathrm{V}_{\mathrm{O}}$ orbitals. Figure 1a shows the schematic diagram of this exchange (the black arrow).

\footnotetext{
* Presented on: 10th International Workshop on Zinc Oxide and Other Oxide Semiconductors, September 11-14, 2018, Warsaw, Poland

${ }^{\dagger}$ corresponding author; e-mail: ccling@hku.hk
}

The $\mathrm{Cu}(+/ 2+)$ is the energy level for the oxidation process $\mathrm{Cu}^{+} \rightarrow \mathrm{Cu}^{2+}+\mathrm{e}$, in which the doubly filled state refers to $\mathrm{Cu}^{+}$and the singly filled state refers to $\mathrm{Cu}^{2+}[3]$. The occupancy of $\mathrm{Cu}^{+}: \mathrm{Cu}^{2+}$ ratio is indeed dependent on the Fermi level position $E_{\mathrm{F}}$. As the FM rises from the $\mathrm{Cu}^{2+}-\mathrm{V}_{\mathrm{O}}-\mathrm{Cu}^{+}$coupling which involves one $\mathrm{Cu}^{2+}$ and one $\mathrm{Cu}^{+}$, it is thus expected that $\mathrm{Cu}^{2+}: \mathrm{Cu}^{+}$equal to $1: 1$ would yield the maximum magnetization. This gives rise to our thought of tuning the magnetization of the $\mathrm{Cu}-$ doped $\mathrm{ZnO}$ sample by changing the Fermi level through resistive switching.
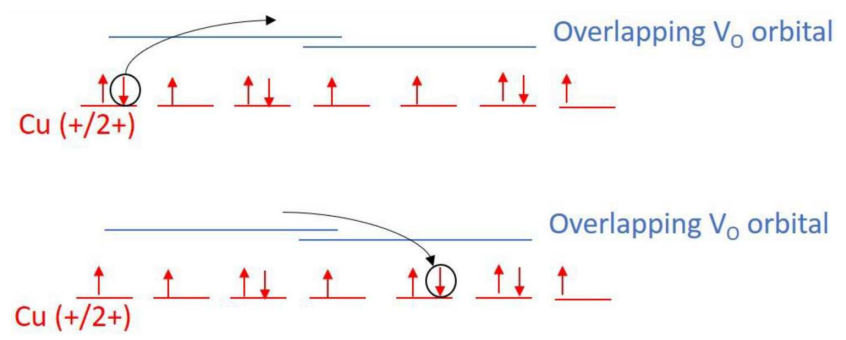

Fig. 1. The schematic diagram showing the $\mathrm{Cu}^{+}-\mathrm{V}_{\mathrm{O}^{-}}$ $\mathrm{Cu}^{2+}$ coupling which leads to the RTFM of $\mathrm{Cu}$-doped $\mathrm{ZnO}$. The coupling involves the hopping of an electron from the $\mathrm{Cu}^{+}$to the $\mathrm{Cu}^{2+}$ through the nearly overlapping $\mathrm{V}_{\mathrm{O}}$ orbital. 


\section{Experiment}

The $\mathrm{Cu}$-doped $\mathrm{ZnO}$ film samples $(\approx 300 \mathrm{~nm}$ thickness) used in this study was grown on $c$-plane sapphire by pulsed laser deposition (PLD) with the details given in $[4,5]$. We have carried out the systematic study on the effect of the different oxygen growth pressure $\mathrm{PO}_{2}$ $(0,0.015,0.020$, and $0.05 \mathrm{~Pa})$ and the $\mathrm{Cu}$ weight compositions in target $(1 \%, 2 \%$, and $4 \%)$. All the samples exhibit wurzite structure with (002) as the preferential direction.

\section{Results and discussion}

Figure 2 shows the data of the magnetization against applied field of the samples with $\mathrm{Cu}=2 \mathrm{wt} \%$ and different $\mathrm{PO}_{2}(=0,0.015,0.020$, and $0.050 \mathrm{~Pa})$ measured at room temperature by a Quantum Design SQUID-VSM. The sample grown with $\mathrm{PO}_{2}=0.02 \mathrm{~Pa}$ is clearly FM at RT which has saturated magnetization of $1.1 \mu_{\mathrm{B}} / \mathrm{Cu}$, and the others are effectively not magnetic. This saturated magnetization is close in magnitude to the value of $\approx 0.5 \mu_{\mathrm{B}} / \mathrm{Cu}$ reported by Herng et al. [2]. The magnetization is very sensitive towards $\mathrm{PO}_{2}$, as magnetic sample is only yielded for the single sample grown with $\mathrm{PO}_{2}=0.02 \mathrm{~Pa}$. In the context of Herng et al. [2] indirect double exchange model, $\mathrm{PO}_{2}$ has influence on the $\mathrm{V}_{\mathrm{O}}$ concentration and the $\mathrm{Cu}^{2+}: \mathrm{Cu}^{+}$ratio. Effective ferromagnetic electron hopping would occur with sufficient $\mathrm{V}_{\mathrm{O}}$ and a good ratio of $\mathrm{Cu}^{+}: \mathrm{Cu}^{2+}$ which is equal to $1: 1$. The resultant magnetization is expected to be sensitive to $\mathrm{PO}_{2}$. Our X-ray absorption (XAS) study confirms that excessive $\mathrm{PO}_{2}$ would yield a low $\mathrm{V}_{\mathrm{O}}$ concentration and too low amount of $\mathrm{PO}_{2}$ would result in too low $\mathrm{Cu}^{2+}: \mathrm{Cu}^{+}$ ratio, and thus would not favor effective ferromagnetic electron hopping. The XAS data is not included in the present manuscript but will be presented in an upcoming manuscript.

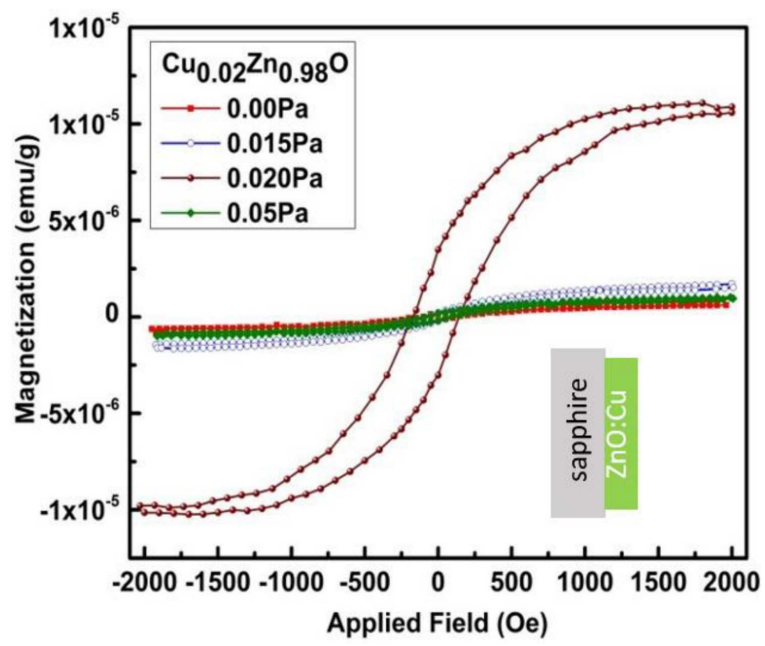

Fig. 2. The magnetization against the applied field for the $\mathrm{Cu}$ doped $\mathrm{ZnO}$ samples grown with different oxygen pressures. The composition of the $\mathrm{Cu}$ is $2 \mathrm{wt} \%$.
Although the sample grown with $\mathrm{PO}_{2}=0.02 \mathrm{~Pa}$ is RTFM, the observation of RTFM is a necessary but not sufficient indication for revealing intrinsic FM as the FM could be originated from the secondary phase. To detect the magnetic secondary phase, we have performed detailed and careful X-ray diffraction study and identified the presence of $\mathrm{CuO}(\overline{1} 11)$ and (022) peaks with very small intensities [4]. Moire's fringe was also identified in transmission electron microscopy (TEM) study, which would indicate the presence of the $\mathrm{CuO}$ nanocrystal with size of $\approx 5-6 \mathrm{~nm}$. Zero-field cooled (ZFC) and fieldcooled (FC) magnetization measurement also coincides with small size $\mathrm{CuO}$ nanocrystal acquiring FM due to the residual spin of $\mathrm{Cu}$ ions at the cluster interfaces $[4,6]$. This implies that $\mathrm{CuO}$ nanocluster contributes for the RTFM, but we cannot exclude the possibility that part of the FM originates from the intrinsic origin.

With the aim to achieve resistive switching tuning magnetization, a sample with the structure of $\mathrm{Al} / \mathrm{ZnO}: \mathrm{Cu} / \mathrm{ZnO}: \mathrm{Ga} /$ sapphire was fabricated with its schematic diagram shown in Fig. 3a. Ga-doped $\mathrm{ZnO}$ (GZO, Ga $=2$ wt $\%$ ) with thickness of $100 \mathrm{~nm}$ and resistivity $\approx 10^{-4} \Omega \mathrm{cm}$ was grown on $c$-plane sapphire by PLD and this thin film was used as the conducting electrode. With $\mathrm{PO}_{2}$ of $0.02 \mathrm{~Pa}, \mathrm{Cu}$-doped $\mathrm{ZnO}(\mathrm{Cu}=$ $2 \mathrm{wt} \%$ ) with thickness of $300 \mathrm{~nm}$ was then grown on the GZO film by PLD. Al metal electrode was then thermally evaporated onto the $\mathrm{ZnO}: \mathrm{Cu}$ film. The $I-V$ data of this structure as shown in Fig. 3a exhibit resistive switching. As the applied bias increases from zero volt the resistance is high (path 1 in Fig. 3). As the applied bias reaches $\approx+1.5 \mathrm{~V}$, the resistance switches to low (path 2 ). The subsequent decrease of applied bias has the memory effect that the resistance keeps low. The resistance of the device can be reset to high resistance by applying a negative bias (paths 4 and 5). The resistances of the high resistance states (HRS) and low resistance states (LRS) are respectively $\approx 1 \mathrm{M} \Omega$ and $\approx 0.1 \mathrm{M} \Omega$. The memory effect is found to be non-volatile. That is after the device is set to low resistance state (LRS) by the $+1.5 \mathrm{~V}$ forward bias and then with the applied bias removed. Then after $5 \mathrm{~h}$, the $I-V$ testing of the device with a small positive bias $<1.5 \mathrm{~V}$ shows that the device is still in the LRS.

Resistive switching in transition metal oxide has been extensively studied with its potential application as resistance random access memory [7]. The resistive switching is attributed to the formation of a conducting filament (like $\mathrm{V}_{\mathrm{O}}$ ), and the electronic properties in the vicinity of the metal/oxide interface [7]. However, it is worthy to bring out that the present sample structure is not quite the same as that used in the typical resistive switching study. The active $\mathrm{Cu}-\mathrm{ZnO}$ layer used in the present study has the thickness of $300 \mathrm{~nm}$ and that in the typical resistive switching device is $\approx 20 \mathrm{~nm}$. It is thus less likely that the formation of the $\mathrm{V}_{\mathrm{O}}$ conducting filament would form through such a long distance in our thick film, and moreover the electric field which drives the $V_{O}$ is smaller in the thick film. Although the mechanism 

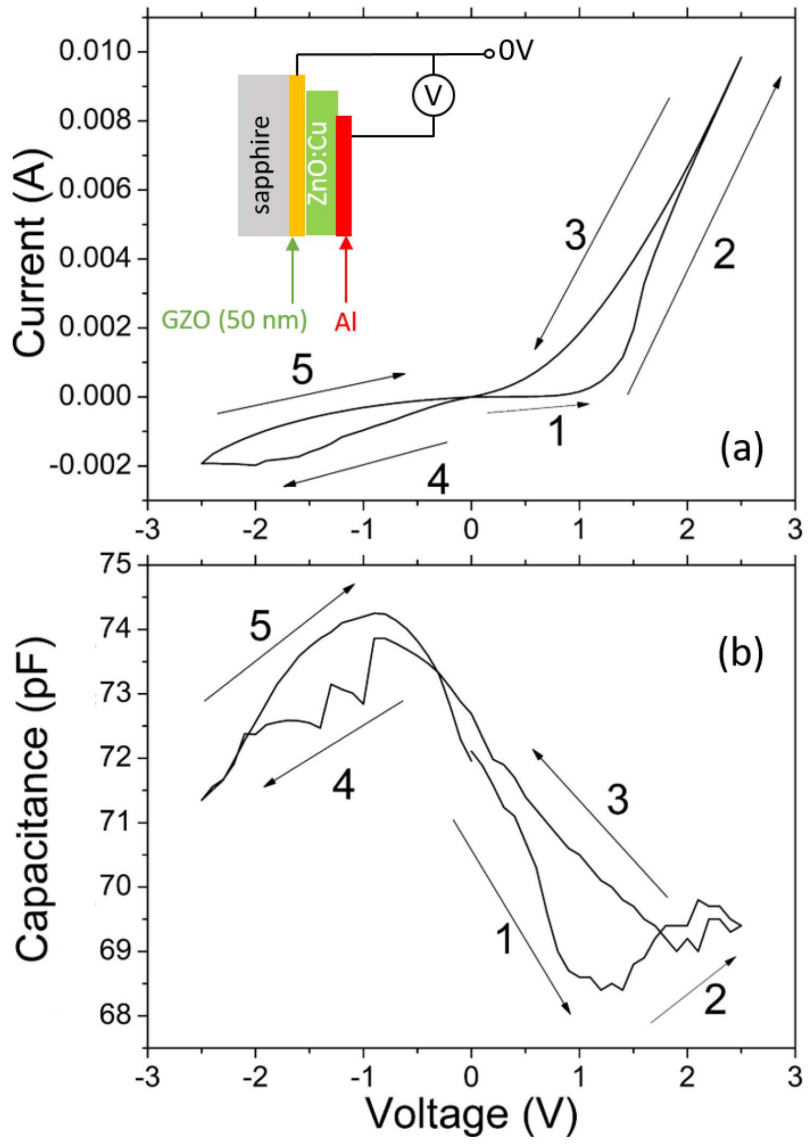

Fig. 3. (a) The $I-V$ data of the $\mathrm{Al} / \mathrm{ZnO}: \mathrm{Cu}(2 \%) / \mathrm{GZO} /$ sapphire cell showing the resistive switching phenomenon. The schematic diagram of the sample structure is shown in the inset. (b) The $C-V$ data of the sample during the setting (to LRS) and resetting (HRS) processes.

leading to the resistive switching reported in the present study still requires further study for understanding the detailed physics behind, it is worthy to carry out the CV measurement to reveal the electronic properties at the interface. Figure $3 \mathrm{~b}$ shows the $\mathrm{CV}$ data corresponding to the set-reset process of the HRS and LRS, for which hysteresis behavior is found. It is noticed that the capacitance in the as-received state (i.e. HRS and path 1 in the figure) is lower than that after setting to LRS (paths 2 and 3). For the Schottky contact, the capacitance $C$ is related to the depletion width $W$ by $C=\varepsilon_{0} \varepsilon_{S} S / W$, where $S$ is the device area. This implies that the depletion width for the HRS is larger than that of the LRS, and thus the tunneling current during the HRS is smaller than that during the LRS. This may explain the observation of the switching.

The SQUID measurement was carried out to characterize the magnetization against the applied field while the sample was as-received (in HRS), set to LRS by applying a positive bias, and then reset to HRS by applying a negative bias [5]. The sample used for studying the magnetic property was slightly different from that used for the resistive switching study, whereas array of $\mathrm{Al} / \mathrm{ZnO}: \mathrm{Cu} / \mathrm{ZnO}: \mathrm{Ga} /$ sapphire cells were fabricated by evaporating an array of $\mathrm{Al}$ metal circular contacts having diameter of $250 \mu \mathrm{m}$, fabricated on top of the $\mathrm{ZnO}: \mathrm{Cu}$ film while each of the $\mathrm{Al}$ metal contacts were separated by $250 \mu \mathrm{m}$ (see inset in Fig. 4). The set voltage for switching all the cells in the array to LRS was $+4 \mathrm{~V}$, and the re-set voltage for switching all the cells in the array from LRS back to HRS was $-4 \mathrm{~V}$. It has been verified that the resistive states upon setting or re-setting were stable for over $5 \mathrm{~h}$ after the external electric bias was removed. The room temperature SQUID measurements were performed immediately after the cell array was set to the resistive state and the applied bias was removed during the SQUID measurement. The details of the experiment can be found in Ref. [5]. The $M-$ $H$ hysteresis curves for the cell array in the as-received state (i.e. HRS), after they were switched to LRS by applying a $+4 \mathrm{~V}$ across the $\mathrm{Al}$ and GZO contacts, and subsequently re-setting back to HRS by applying a $-4 \mathrm{~V}$ were shown in Fig. 4. The saturated magnetic moment of the cell array in the as-received state (i.e. in HRS) is $2.1 \times 10^{-6} \mathrm{emu}$, and it drops to $1.6 \times 10^{-6} \mathrm{emu}$ after the cells were set to LRS by applying the $+4 \mathrm{~V}$, then increases back to $2.0 \times 10^{-6}$ emu after the cells were re-set back to HRS by applying the $-4 \mathrm{~V}$. The saturated magnetizations of the different resistance states were tabulated in Table I.

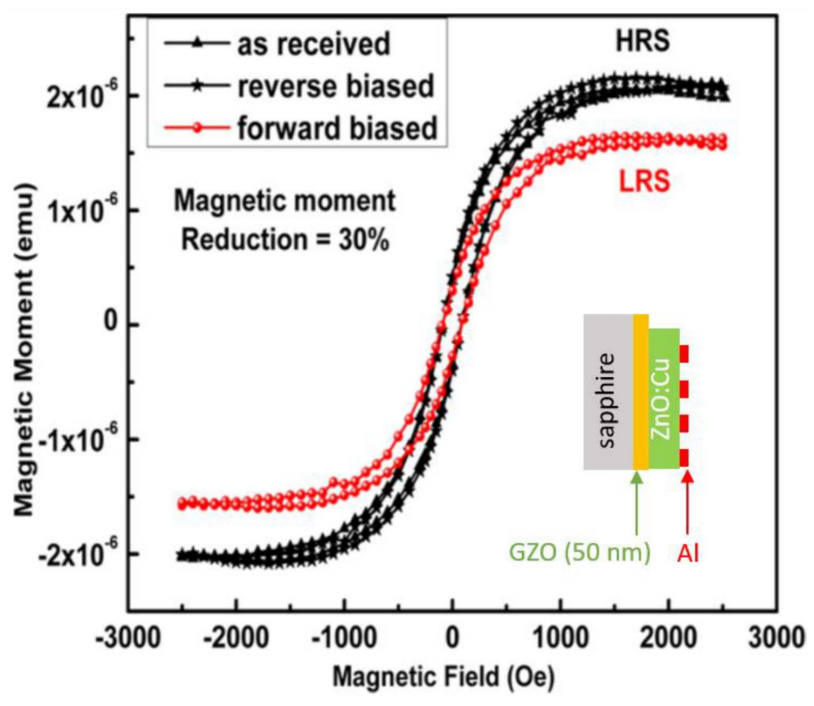

Fig. 4. Room temperature $M-H$ curves for the cell array sample in the states of as-received (HRS), set to LRS by applying $+4 \mathrm{~V}$, and then re-set back to HRS by applying $-4 \mathrm{~V}$. The schematic diagram of the cell array sample is shown in the inset.

XPS was carried out to reveal the $\mathrm{Cu}^{+}: \mathrm{Cu}^{2+}$ ratios while the cell array was in the states of as-received (HRS), set to LRS by applying the $+4 \mathrm{~V}$, and then re-set back to HRS by applying the $-4 \mathrm{~V}$. The $\mathrm{Cu}^{+}: \mathrm{Cu}^{2+}$ ratio is obtained by fitting the intensities of the $\mathrm{Cu}^{+}$and 
TABLE I

The relative saturated magnetization, $\mathrm{Cu}^{+}: \mathrm{Cu}^{2+}$ ratio and relative $\mathrm{V}_{\mathrm{O}}$ intensity of the $\mathrm{Al} / \mathrm{ZnO}: \mathrm{Cu}$ /GZO/sapphire sample while as-received (HRS), set to LRS by applying positive bias, and then reset to HRS by applying reverse bias.

\begin{tabular}{l|c|c|c}
\hline \hline & $\begin{array}{c}\text { Saturated } \\
\text { magnetic } \\
\text { moment [emu] }\end{array}$ & $\begin{array}{c}\mathrm{Cu}^{+}: \mathrm{Cu}^{2+} \\
\text { ratio }\end{array}$ & $\begin{array}{c}\text { Relative } \mathrm{V}_{\mathrm{O}} \\
\text { intensity }\end{array}$ \\
\hline $\begin{array}{l}\text { as-received HRS } \\
(\approx 1 \mathrm{M} \Omega)\end{array}$ & $2.1 \times 10^{-6}$ & 4.4 & 1 \\
$\begin{array}{c}\text { +ve bias set to LRS } \\
(\approx 0.1 \mathrm{M} \Omega)\end{array}$ & $1.6 \times 10^{-6}$ & 6.9 & 0.98 \\
$\begin{array}{l}\text {-ve bias reset to HRS } \\
(\approx 1 \mathrm{M} \Omega)\end{array}$ & $2.0 \times 10^{-6}$ & 4.6 & 1.02 \\
$\quad$ & &
\end{tabular}

$\mathrm{Cu}^{2+}$ components of the $\mathrm{Cu} 2 p_{3 / 2}$ and the $\mathrm{Cu} 2 p_{1 / 2}$ XPS spectra and the details and XPS spectra were shown in Ref. [5]. The results are tabulated in Table $\mathrm{I}$. $\mathrm{Cu}^{+}$is significantly more than $\mathrm{Cu}^{2+}$ irrespective of the resistance states. As the device is switched from as-received HRS to LRS by applying the +ve bias, the $\mathrm{Cu}^{+}: \mathrm{Cu}^{2+}$ ratio increases from 4.4 to 6.9 . As the device is then reset from the LRS to the HRS by applying the - ve bias, the $\mathrm{Cu}^{+}: \mathrm{Cu}^{2+}$ ratio restores to the value of 4.6 which is close that of the as-received HRS.

To monitor the $\mathrm{V}_{\mathrm{O}}$ while the sample was in the different resistance states, the O $1 s$ XPS spectra were fitted with three Gaussians. The intensities of the $\mathrm{V}_{\mathrm{O}}$ related component while the device was at different resistance states are tabulated in Table I. No significant change in the relative $\mathrm{V}_{\mathrm{O}}$ intensity is observed irrespective of the resistance states.

As summarized in Table I, the saturated magnetization and the $\mathrm{Cu}^{+}: \mathrm{Cu}^{2+}$ ratio are dependent on the resistance state of the device, for which the relative saturated magnetization and the $\mathrm{Cu}^{+}: \mathrm{Cu}^{2+}$ are respectively $\approx 1.0$ and $\approx 4.5$ while in the HRS, and equal to $\approx 0.7$ and 6.9 while in the LRS. It would be worthy to discuss the physics behind the resistive switching tuning magnetization. The RTFM of $\mathrm{Cu}$-doped $\mathrm{ZnO}$ is attributed to the carrier hopping between the $\mathrm{Cu}^{2+}$ and $\mathrm{Cu}^{+}$through the nearby $\mathrm{V}_{\mathrm{O}}$ orbital [2]. As in such a $\mathrm{Cu}^{2+}-\mathrm{V}_{\mathrm{O}^{-}} \mathrm{Cu}^{+}$ coupling, one $\mathrm{Cu}^{2+}$ and one $\mathrm{Cu}^{+}$are involved. It implies that maximum coupling and thus magnetization will result if the $\mathrm{Cu}^{+}: \mathrm{Cu}^{2+}$ ratio is equal to unity. The $\mathrm{Cu}^{+}: \mathrm{Cu}^{2+}$ is always significantly larger than 1 either in the HRS and LRS. Switching from HRS to LRS results in more carrier injection and thus the Fermi level moves towards the conduction band. This would increase the $\mathrm{Cu}^{+}$occupancy and decrease that of the $\mathrm{Cu}^{2+}$, and thus increase the $\mathrm{Cu}^{+}: \mathrm{Cu}^{2+}$ ratio. This deduction is also confirmed by the experimental XPS measurement. While the $\mathrm{V}_{\mathrm{O}}$ concentration does not significantly change with the resistance state, increase of $\mathrm{Cu}^{+}: \mathrm{Cu}^{2+}$ ratio implies even more deviation from the 1:1 ratio (corresponding to maximum magnetization) and thus the saturated magnetization drops.
Photoluminescence characterization of the samples at HRS and LRS were performed at $10 \mathrm{~K}$. To facilitate the $\mathrm{PL}$ experiment, the sample configuration is shown in the inset of Fig. 5. The excitation laser is incident from the side of the sapphire. The thicknesses of the GZO and $\mathrm{ZnO}: \mathrm{Cu}$ layers are respectively $50 \mathrm{~nm}$ and $400 \mathrm{~nm}$. The PL spectra taken at HRS and LRS have the same luminescence peaks but the intensities are different. NBE peaks of $3.15,3.22$, and $3.32 \mathrm{eV}$, and defect emission at $\approx 2.36 \mathrm{eV}$ are observed in both of the spectra. $I-V$ measurement was conducted after the PL measurement and it was found that the resistance state was not changed by the PL measurement. As the $\mathrm{ZnO}: \mathrm{Cu}$ film has thickness as $400 \mathrm{~nm}$, the PL signal is originated from the GZO films, the $\mathrm{GZO} / \mathrm{ZnO}: \mathrm{Cu}$ interface, or the $\mathrm{ZnO}: \mathrm{Cu}$ film, but not from the $\mathrm{ZnO}: \mathrm{Cu} / \mathrm{Al}$ interface. However, the $\mathrm{PL}$ peaks found in the present sample are also found in the $\mathrm{PL}$ spectrum of the bare $\mathrm{Cu}$-doped $\mathrm{ZnO}$ sample grown in the same condition but not in that of the bare GZO sample. This implies that the PL signal observed here originates from the depletion region or the bulk in the $\mathrm{ZnO}: \mathrm{Cu}$ film.

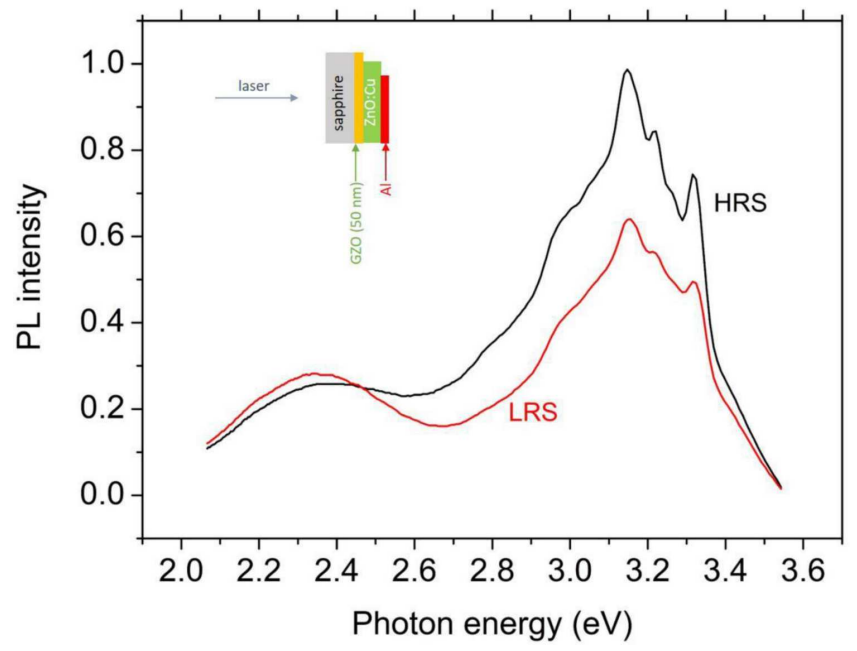

Fig. 5. The $10 \mathrm{~K}$ PL spectra of the $\mathrm{Al} / \mathrm{ZnO}: \mathrm{Cu}(2 \%)$ /GZO/sapphire cell while set at HRS and LRS. The schematic diagram of the sample is shown in the inset.

With the sample switching from HRS to LRS, the NBE intensity drops by $\approx 30 \%$. This change is not artifactitious effect (for example due to different optical alignment) as the defect emissions at HRS and LRS are effectively the same. The NBE emissions $3.22 \mathrm{eV}$ and its corresponding first phonon replica at $3.15 \mathrm{eV}$ have also been observed in undoped $\mathrm{ZnO}$ sample grown with the similar methods [8]. The $3.22 \mathrm{eV}$ emission has been related to the donor-acceptor-pair (DAP) transition. The other NBE emission at $3.32 \mathrm{eV}$ has photon energy lower than that of the donor bound exciton or the acceptor bound exciton (which is commonly reported to be larger than $3.35 \mathrm{eV}$ ). Peaks at $3.312 \mathrm{eV}$ and $3.332 \mathrm{eV}$ have been identified and probably originate due to excitons bound 
to structural defects (pages 44 and 45 in [1]). As the sample is switched from HRS to LRS, the depletion width decreases. Some defects (say donor) located in the depletion region during the HRS may change their charge state by emitting an electron to the conduction band during the shrinking of the depletion width. If this defect is involved in the transitions of the NBE emissions, change of charge state may cause the corresponding photon emitting transition processes to be no longer feasible and thus the NBE emission intensity decreases. However this explanation is speculative and further investigation is needed to explore the physics behind.

\section{Conclusion}

Resistive switching tuning RT FM was observed in $\mathrm{Cu}$-doped $\mathrm{ZnO}$ based structure. Switching from HRS to LRS results in reduction of saturated magnetization. The change of the RT FM is due to the increase of the $\mathrm{Cu}^{+}: \mathrm{Cu}^{2+}$ occupancy which reduce the $\mathrm{Cu}^{+}: \mathrm{V}_{\mathrm{O}}: \mathrm{Cu}^{2+}$ coupling which leads to the RTFM. Switching from HRS to LRS also leads to the reduction of the NBE emission intensity, which is speculated to be related to the change of charge state of the defects involved in the NBE emission transitions.

\section{Acknowledgments}

This work is financially supported by the HKSAR RGC GRF (17302115).

\section{References}

[1] Ü. Özgür, Ya.I. Alivov, C. Liu, A. Teke, M.A. Reshchikov, S. Dogan, V. Avrutin, S.-J. Cho, H. Morkoç, J. Appl. Phys. 98, 041301 (2005).

[2] T.S. Herng, D.-C. Qi, T. Berlijn, J.B. Yi, K.S. Yang, Y. Dai, Y.P. Feng, I. Santoso, C. SĂAnchez-Hanke, X.Y. Gao, A.T.S. Wee, W. Ku, J. Ding, A. Rusydi, Phys. Rev. Lett. 105, 207201 (2010).

[3] M.D. McCluskey, S.J. Jokela, J. Appl. Phys. 106 , 071101 (2009).

[4] M. Younas, J. Shen, M. He, R. Lortz, F. Azad, M.J. Akhtar, A. Maqsood, F.C.C. Ling, $R S C A d v$. 5, 55648 (2015).

[5] M. Younas, C. Xu, M. Arshad, L.P. Ho, S. Zhou, F. Azad, M.J. Akhtar, S. Su, W. Azeem, F.C.C. Ling, ACS Omega 2, 8810 (2017).

[6] A. Punnoose, H. Magnone, M.S. Seehra, J. Bonevich, Phys. Rev. B 64, 174420 (2001).

[7] A. Sawa, Mater. Today 11, 28 (2008).

[8] Z. Wang, S.C. Su, M. Youans, F.C.C. Ling, W. Anwand, A. Wagner, RSC Adv. 5, 12530 (2015). 